\title{
La nueva teoría desarrollista: una síntesis ${ }^{\mathbf{1}}$ The new developmental theory: a synthesis
}

Journal of Economic Literature (JEL): O21, 054, 05

Palabras clave:

Economía internacional

Política de planificación

América Latina

Estudios económicos globales

Keywords:

International Economics

Planning Policy

Latin America

Economywide Country Studies

Fecha de recepción:

11 de agosto de 2016

Fecha de aceptación: 2 de diciembre de 2016

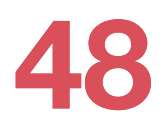

ECONOMÍAunam vol. 14 núm. 40, enero-abril, 2017

\section{Resumen}

El nuevo desarrollismo nace del fracaso económico y político de la globalización, la financiarización y el neoliberalis-

mo. En los países en desarrollo pretende garantizar la democracia, la reducción de las desigualdades y la protección al medio ambiente. Es una estrategia nacional que le otorga al Estado un papel central, y como condición indispensable, propone una dirección sólida y eficiente; pues no cree que el mercado pueda resolverlo todo, ni que las instituciones deban limitarse a garantizar la propiedad privada y el cumplimiento de los contratos. El nuevo desarrollismo es un sistema teórico incluyente, heredero del desarrollismo clásico, con propuestas actualizadas que le permitirán a los países de mediano desarrollo tener los elementos para acercarse en mejores condiciones a las naciones más prósperas.

\section{Abstract}

The new developmentalism arises from the economic and political failure of globalization, financialization and neoliberalism. In developing countries it seeks to guarantee democracy, reduce inequalities and protect the environment. It is a national strategy that gives the State a central role, and as an indispensable condition, proposes a solid and efficient direction; Because it does not believe that the market can solve everything, nor that the institutions should confine themselves to guaranteeing private property and the fulfillment of contracts. The new developmentalism is an inclusive theoretical system, heir to the classical developmentalism, with updated proposals that will allow the medium-developing countries to have the elements to approach in better conditions to the more prosperous nations.

1 Agradezco a Ricardo Bielschowsky y a Marco Capraro Brancher sus observaciones para mejorar la versión. 
e puede considerar al desarrollismo de dos distintas maneras: a) como una forma de organización económica y política capitalista alternativa al liberalismo económico, y el correspondiente estilo de gestión económica del capitalismo; y b) como una escuela de pensamiento económico. En este segundo caso, el nuevo desarrollismo es un sistema teórico que se origina en la economía política clásica, la teoría económica keynesiana y el desarrollismo clásico. Como una forma de capitalismo, se manifiesta por primera vez durante el mercantilismo. Así, la teoría está presente específicamente en el desarrollismo clásico (originalmente llamada economía del desarrollo, en América Latina, el estructuralismo) y el nuevo desarrollismo.

Históricamente había dos formas de Estado en el capitalismo: la liberal y desarrollista-liberal en la medida en que el Estado es limitado, en términos económicos, para garantizar los derechos de propiedad y los contratos, así como para administrar responsablemente sus facturas de impuestos; desarrollista si, además, también interviene moderadamente en el mercado para adoptar un nacionalismo económico razonable en la competencia entre los estados-nación. El desarrollismo considera un Estado en el cual una coalición de la clase política se enfrenta al desarrollo económico y tiene en su núcleo a la burguesía industrial; donde se supone que los trabajadores urbanos industriales son relativamente "nacionalista" y forman parte de la burocracia pública. Para las tres clases de desarrollo económico se entiende como un cambio estructural, inicialmente en la forma de llevar a cabo la industrialización, y más tarde, la especialización productiva, cuando surgen los servicios que se caracterizan por una tecnología compleja, personal calificado, con valor agregado per cápita alto, y por consiguiente, con un aumento de los salarios. Esta coalición o pacto político desarrollista ve al sistema capitalista no sólo como un sistema de competencia entre las empresas, sino también entre los estados-nación. Del mismo modo que las empresas necesitan estrategias de gestión para tener éxito en la competencia, los estados-nación también tienen que definir las estrategias de desarrollo. La prioridad para las empresas es el lucro, el medio ambiente, la innovación schumpeteriana, en cambio, para los países se privilegia el desarrollo económico, el medio ambiente y la acumulación de capital mediante la incorporación de progreso técnico.

El desarrollo económico requiere de un aumento sostenido de los salarios y del nivel de vida de la población o, en otras palabras, el aumento de la productividad del trabajo y el ingreso per cápita. Sólo a través de una mayor productividad se puede garantizar mejores niveles de vida de la población. Pero el progreso o el desarrollo humano es un proceso histórico más amplio que el desarrollo económico. La seguridad y el orden interno ya eran objetivos del antiguo Estado. A partir del siglo XVIII, en el contexto de la revolución capitalista, seguian siendo los cuatro principales objetivos políticos de las sociedades modernas, sucesivamente definidos y garantizados: primero, el objetivo de la libertad individual, lo que llevó al liberalismo económico; en segundo lugar, a partir de la revolución industrial, el desarrollo económico que dio origen al nacionalismo económico o desarrollismo; en tercer lugar, a partir de la segunda mitad del siglo XIX, la justicia social, que se originó en el socialismo; y, por último, a partir de la segunda mitad del siglo XX, la protección de la naturaleza, lo que dio lugar al ambientalismo. El desarrollo humano o el progreso es el proceso histórico por 
el cual cada Estado-nación se mueve hacia estos cinco grandes objetivos políticos. Para llegar a ellos el instrumento de acción colectiva por excelencia de cada nación es el Estado, y su acción humana correspondiente es la acción política. A través de la política cada nación define las instituciones formales del país y sus leyes, así como sus políticas públicas, y con ello se mueve en la dirección del progreso.

Una economía nacional es un sistema de coordinación que se ejerce sobre el nivel micro de las empresas y los individuos y en el plano macroeconómico de los agregados económicos. Esta coordinación debe ser eficiente a nivel micro, cuando hay competencia entre las empresas y otros agentes económicos; el mercado es la institución de coordinación más eficiente; como es el caso de las empresas de infraestructuras, empresas de petroquímicos básicos y los grandes bancos "demasiado grandes para quebrar", en realidad el mercado y el Estado debe coordinar acciones sólidas a través de la planificación y la regulación. En el plano macroeconómico el mercado definitivamente no puede garantizar que los precios macroeconómicos sean favorables lograr el pleno empleo y el crecimiento. Por eso, el nuevo desarrollismo establece que el Estado debe desempeñar una política macroeconómica activa, sobre todo la política de tipo de cambio, para que ciertos precios macroeconómicos sean viables.

El nuevo desarrollismo es una teoría histórico-deductivo que, dentro del marco de imprevisibilidad e incertidumbre que caracteriza el comportamiento humano, busca entender cómo los países de la periferia del capitalismo comenzaron a buscar el desarrollo económico y cosechar logros después de la Segunda Guerra Mundial. Por lo tanto rechaza el método hipotético-deductivo de la teoría económica neoclásica, modelo de equilibrio general, y la posibilidad de que los sistemas económicos sean simplemente regulada por el mercado. En su lugar, se afirma la existencia de sistemas económicos nacionales y la formación de un sistema económico mundial, que se rige por dos instituciones clave -el Estado y el mercado- ambas reguladas por el Estado.

Economía política La economía política del nuevo desarrollismo estudia el desarrollismo realmente existente, trata de entender al Estado y a las coaliciones de clase desarrollistas, así como las formas que el capitalismo asumió a partir del siglo XVI. Hoy, en lo económico, el capitalismo ha demostrado ser insustituible debido a que el mercado es un sistema superior al Estado en la coordinación de las acciones de las empresas competitivas. Pero en la sociedad moderna existe una gran industria no competitiva en la que la coordinación del Estado es esencial. Así que en los sistemas capitalistas tenemos dos sectores: uno competitivo, coordinados por el mercado, y un monopolista, coordinado por el Estado. Prevalece aquí el principio de subsidiariedad: lo que hace bien el mercado, que el Estado se abstenga de interferir. Esto, a nivel microeconómico. En el plano macroeconómico definitivamente el mercado no es capaz de asegurar que los cinco precios macroeconómicos sigan siendo viables: las tasas de ganancia, tasas de interés, tipos de cambio, los salarios y la inflación. Por lo tanto, el papel del Estado también es fundamental en la política macroeconómica. 
Para el nuevo desarrollo, el desarrollismo es el camino "por defecto" del capitalismo, pues vino con el mercantilismo. Luego tuvimos varios modelos o formas de Estado en el capitalismo desarrollista, que pueden clasificarse de acuerdo con el período histórico en que sucedieron y a que fueran ubicadas como de "centro" o "periférica", es decir, de acuerdo con tener que enfrentar o no al imperialismo moderno de los primeros países industrializados para llevar a cabo su revolución industrial y capitalista.

Teniendo en cuenta a los países que han hecho de su revolución, se puede distinguir las siguientes formas de desarrollismo y sus respectivos países. ${ }^{2}$

1. El mercantilismo: fue el primer desarrollismo; define a los países centrales que originalmente hicieron su revolución industrial y capitalista y que fueron los primeros en llegar a ser ricos: Gran Bretaña y Francia.

2. Bismarckismo: caracteriza la revolución industrial en los países centrales atrasados como Alemania y Estados Unidos; países que también se han enriquecido.

3. Desarrollismo periférico independiente: países de Asia oriental, a partir del modelo japonés; estos países han adoptado el término o están completando la puesta al día, y muchos ya son ricos y se han convertido en parte de los países centrales.

4. Desarrollismo nacional: caracteriza a la revolución industrial y capitalista en los países periféricos como nacional-dependiente, es decir, países como Brasil y Turquía que no han logrado superar su dependencia de los países ricos; estos países son ahora los países de ingresos medios.

5. Desarrollismo socialdemócrata o de la edad de oro del capitalismo: fue el segunda desarrollismo entre los países ricos; se inició con el New Deal y Europa en Estados Unidos después de la guerra; entre la primera y la segunda; fue un período liberal, que era relativamente largo en los países centrales de desarrollo original y breve en los países centrales del desarrollo atrasado. 3

Todos los países han hecho su revolución industrial y capitalista en el contexto de un desarrollismo autoritario o simplemente autoritario-liberal. En ninguno de ellos se garantiza el sufragio universal en el momento de la revolución industrial. Sin embargo, esto no significa que el desarrollismo sólo sea posible en un contexto de regímenes autoritarios. El desarrollismo tuvo un origen autoritario, pero que era democrático en la edad de oro; de tal modo que el liberalismo nació con un rechazo a la idea de democracia, pero finalmente la aceptó cuando la presión popular a sus ventaja superó los temores de la burguesía a la "tiranía de la mayoría". Hoy en día, los países preindustriales enfrentan una dificultad adicional, porque no tienen más remedio que aceptar el punto de vista económico o realizar su revolución capitalista en el contexto de la democracia. ${ }^{4}$

2 Para hacer esta clasificación del desarrollismo me basé en un modelo que he desarrollado en otro artículo: "Modelos de estado de desarrollo" (Bresser-Pereira 2016a).

3 Tomando al Reino Unido como una referencia, el liberalismo económico se prolongó desde 1834, cuando abrió su economía, hasta 1929; ya en el Alemania liberalismo económico duró desde finales del siglo XIX hasta 1929.

4 Ver "Democracy and development in pre-industrial countries" (Bresser-Pereira 2016b). 
Para el nuevo desarrollismo el papel económico del Estado es garantizar las condiciones generales de la acumulación de capital, o, en otras palabras, es garantizar los medios necesarios para que las empresas puedan invertir y aumentar continuamente su productividad. Entre esas condiciones, cinco son esenciales: 1) El orden público, la seguridad de la propiedad y el contrato, 2) La educación pública, 3) La promoción de la ciencia y la tecnología, 4) Las inversiones en infraestructura económica y 5) Un tipo de cambio que hace que las empresas competitivas utilicen la mejor tecnología disponible en el mundo. Además del desarrollo económico, el Estado democrático debe garantizar la seguridad, la libertad individual, la reducción de la desigualdad, y la protección del medio ambiente. Los otros objetivos políticos se han convertido en importantes con el consenso en la sociedad contemporánea. El capitalismo nació con el primer desarrollismo: en el mercantilismo, cuando surgió la revolución industrial en Inglaterra, Francia y Bélgica. $Y$ hasta la fecha, ha demostrado ser una forma de organización del más alto nivel y nos lleva hacia el liberalismo económico, excepto cuando se trata de coordinar al sector no competitivo de cada economía nacional. Sin embargo, desde hace un siglo, entre 1830 y 1929, el liberalismo económico fue dominante en los países centrales. Fue un período de bajo crecimiento y muchas crisis económicas, que terminó con la caída de la bolsa en 1929 y la Gran Depresión, el segundo desarrollismo siguió el New Deal, la edad de oro del capitalismo, el de Bretton Woods y el Pacto de Estado Social. Pero en la década de 1970 el segundo desarrollismo enfrentó una crisis por no lograr el control satisfactorio de la inflación y, principalmente, por que dejó de garantizar las tasas de ganancia lucrativas para las empresas. Al mismo tiempo, el capitalismo en el mundo estaba experimentando una transformación importante -la globalización- es decir, el proceso histórico en el que surgen las empresas manufactureras y de servicios multinacionales. Ellas ocupan los mercados en todos los países, y las burguesías de los países centrales dejan de ser empresarios locales, para convertirse en rentistas y financieros, que tienen como fuente de sus ingresos principalmente los beneficios obtenidos en el mercado interno de cada país, y obtener dividendos e intereses a través de las compañías multinacionales en los mercados de otros países.

La disminución de las ganancias y la estanflación de la década de 1970, así como la globalización, marcaron la segunda crisis del desarrollismo y, a partir de 1979, dieron lugar a la etapa neoliberal del capitalismo. Al contrario de que los intelectuales neoliberales predijeron, este liberalismo económico radical y reaccionario se caracterizó por un bajo crecimiento, gran inestabilidad financiera, y un fuerte aumento de la desigualdad, en comparación con los años de oro. Desde 2008 el neoliberalismo enfrenta una grave crisis económica, que ha empeorado desde 2010 con la crisis del euro. Y desde 2016, el neoliberalismo global también se enfrenta a una crisis política de grandes proporciones, expresada en Brexit, en la postulación de Donald Trump para el presidente, y en el creciente poder de la extrema la derecha en Europa. Hoy vivimos en un contexto de crisis económica que se expresa en cuasi-estancamiento y en una profunda crisis política que muy probablemente conducirá el mundo rico a pensar en un tercer desarrollismo, cuyas características están aún por definirse. 
En cuanto a los países en desarrollo, el crecimiento económico sigue siendo satisfactorio sólo en el Este de Asia e India. No hay enfermedad holandesa en aquellos países, y sus élites económicas y políticas, continúan preparandose para crecer productivamente. En cuanto a los países latinoamericanos y africanos, que tienen la enfermedad holandesa y no lograron neutralizarla desde la década de 1990, acataron el liberalismo económico del Consenso de Washington, el crecimiento sólo fue satisfactorio en la década de 2000 gracias a un boom de las commodities causados por el aumento de la demanda china. Sin embargo, de continuar con tal tendencia, se desindustrializarán como parte de tal dependencia y no habrá futuro para ellos.

\section{El desarrollismo clásico} dor, como una reacción y como un intento de explicar las grandes dificultades que no sólo los países periféricos -especialmente de medianos ingresos-, sino también los preindustriales, están encontrando para desarrollar e implementar el crecimiento.

Esta tarea recayó originalmente en el desarrollismo clásico. Surgió en el Reino Unido en la década de 1940, con la transición de la Sociedad de las Naciones a las Naciones Unidas, bajo el nombre de "economía del desarrollo", y en América Latina, con el nombre de "estructuralismo latinoamericano", que define al desarrollo económica como "cambio estructural". Hoy, prefiero llamarlo desarrollismo clásico. Era la teoría dominante de desarrollo económico entre los años 1940 y 1960 y tenía entre sus representantes destacados a: Rosenstein, Rodan, Raúl Prebisch, Arthur Lewis, Albert Hirschman y Celso Furtado. Su objetivo era promover el desarrollo económico de los países subdesarrollados o periféricos, que todavía no habían llevado a cabo su revolución industrial capitalista.

Las principales contribuciones de desarrollismo clásico eran, en el plano político, el desarrollo económico, entendido como el resultado de una coalición de clases que incluyera a la burguesía nacional, la burocracia pública y los trabajadores urbanos; y, en el plano económico, el desarrollo económico entendido como "cambio estructural", es decir, como la industrialización que pudiera transformar a las estructuras de la sociedad.

Esta industrialización inicialmente proponía sustituir importaciones, y tenía como justificación el impulso de la naciente industria que destacaron Alexander Hamilton y Friedrich List, la tendencia al deterioro de los términos de intercambio y del modelo de restricción externa, debido a las diferentes elasticidades de ingresos para los países en desarrollo; Prebisch (1949), y la teoría del "subdesarrollo" de Furtado (1961) para el cual el subdesarrollo en la periferia del capitalismo no se compone de los países "atrasados", sino de los países dependientes o subordinados respecto a los países desarrollados. La condición de subdesarrollo es coetáneo con el desarrollo, y sólo se puede superar con la adopción de una estrategia nacional de desarrollo dirigido por el Estado.

De hecho, éste es siempre el papel del Estado: proporcionar a los agentes privados las condiciones generales para la innovación y la acumulación de capital. El desarrollismo clásico defendió una fuerte protección a la producción nacional para 
hacer viable el modelo de industrialización basado en la sustitución de importaciones. Sus economistas intuyeron la existencia de una enfermedad holandesa que apreciaba en el largo plazo, la tasa de cambio del país, pero prefieren hacer frente a este problema con las altas tasas, tipos de cambio múltiples, y, en Brasil, entre 1967 y 1990 con subsidios a sus exportaciones. No percibieron que a través de un impuesto a la exportación de commodities de acuerdo con el precio internacional de los mismos se garantizaba a los exportadores un ingreso estable y satisfactorio, al mismo tempo que asegurar las otras empresas industriales la igualdad de condiciones en la competencia con las empresas los otros países. 5

¿Cómo explicar de manera práctica, porque se tomaban de medidas, como fue el caso de "la confiscación de cambio" en Brasil, lo que efectivamente neutraliza la enfermedad holandesa? Probablemente porque para las autoridades de la época no había ninguna duda de que el desarrollo económico es la industrialización, y por lo tanto, pragmaticamente, adoptaron las medidas que conducian al país en esta dirección.

La crisis del desarrollismo clásico comenzó a finales de 1960 con la aparición de la teoría de la dependencia, esto es una reacción a los golpes militares modernizadores que tienen lugar en América Latina en la década de 1960. Esta teoría o interpretación de la dependencia excluye la posibilidad de una burguesía nacional y de una revolución burguesa, y es una versión "asociada" que promueve la asociación, es decir, la subordinación de los países en desarrollo a los poderes imperiales modernos. Su crisis se profundizó desde mediados de la década de 1970, cuando vuelve a ser dominante en las universidades la teoría económica neoclásica y, por lo tanto, los modelos de crecimiento ahistóricos para sustituir el análisis estructuralista del desarrollo económico. Albert Hirschman escribió un "Epitafio" del desarrollismo clásico en 1981, en un artículo con un título significativo: "Auge y decadencia del desarrollismo clássico". ${ }^{6}$ La crisis del desarrollismo clásico se convierte en definitiva a partir de la década de 1980, cuando la teoría económica neoclásica y la ideología neoliberal se vuelven dominantes, el proyecto de industrialización se abandona porque se considera "innecesario" para el crecimiento económico, y en la década de 1990 son adoptados las reformas neoliberales por todos los países de la periferia del capitalismo, con excepción de los países del Este de Asia y la India. La nueva consigna fue: desnacionalización, privatización y desregulación.

Desde su nacimiento en 1943, con la propuesta de el "gran empuje"7 el desarrollismo clásico incurre en el gran error de la defensa de la política de crecimiento con deuda ("ahorros") externos. Un error que retrasa el crecimiento de América Latina y, en la década de 1980, fue la causa de una gran crisis financiera, la crisis de la deuda externa de la década de 1980 interrumpió el crecimiento de los países en desarrollo y

5 Sobre el escepticismo de desarrollo clásico, sobre todo Prebisch, un tipo de cambio competitivo ver Bresser-Pereira ver Rugitsky (2016).

6 Ver "The rise and decline of development economics" (Albert O. Hirschman 1981).

7 Ver "Problems of industrialization in Eastern Europe and South-Eastern Europe" (RosensteinRodan 1943). 
que llevó a sus élites a abandonar el desarrollismo clásico y para abrazar la ortodoxia liberal y semiestancamiento, esto sólo fue interrumpido en tiempos de auge de los commodities.

Surge el nuevo desarrollismo Los mercados financieros -que se habían cerrados para los países en desarrollo-, de

nuevo fueron abiertos en la década de 1970, y hacían una apuesta al endeudamiento externo para crecer. Este crecimiento se dio en el corto plazo, pero en la siguiente década enfrentaron una grave crisis financiera -la gran crisis de la deuda externa-, con un fuerte aumento de la inflación, y un estancamiento en sus economías. Algunos países, como Argentina y Brasil; que luego hicieron su transición a la democracia, y el nuevo gobierno, inspirado por el desarrollismo clásico y la macroeconomía keynesiana, trataron de reanudar el desarrollo, pero cedieron a la alta preferencia para el consumo inmediato expresado en populismo fiscal (déficit públicos irresponsables) y fracasó, y así dieron espacio para la entrada del Consenso de Washington. En la segunda mitad de la década de 1980, las reformas neoliberales comenzaron a ser adoptado en México, y en la siguiente década, se han implementado en toda la región. Las políticas de ajuste fiscal han contribuido a controlar la inflación -que en algunos países habían subido mucho-, pero pronto se hizo evidente que la ortodoxia liberal estuvo marcado por un segundo tipo de populismo, el tipo de cambio populista, es decir, déficit en cuenta corriente también irresponsables que implicaban una apreciación del tipo de cambio, el aumento del consumo, desaliento a la inversión, y en última instancia, crisis de la balanza de pagos.

Fue en este desalentador panorama -los fracasos tanto del populismo desarrollista keynesiano, como el populismo liberal ortodoxo- que un creciente grupo de economistas y yo propusimos el nuevo desarrollismo. En la década de 1990, el fracaso del desarrollismo en el gobierno de José Sarney y el fracaso de la ortodoxia liberal en el gobierno de Fernando Henrique Cardoso en Brasil, el fracaso repetitivo de la ortodoxia liberal de los gobiernos de Miguel de la Madrid y Carlos Salinas, en México; y el fracaso del desarrollismo en el gobierno de Raúl Alfonsín y la ortodoxia liberal del gobierno de Carlos Menem en Argentina, me llevaron, durante la década de 2000, a la convicción de que ni el desarrollismo clásico y post-keynesianismo (inicialmente llamado "viejo" desarrollismo) ni ortodoxia liberal, ofrecían herramientas teóricas para comprender el cuasi-estancamiento de la economía brasileña, y, más en general, de las economías de América Latina, como el semiestancamiento, cuya naturaleza es esencialmente macroeconómica. El nuevo desarrollismo viene a principios de la década de 2000 como una reacción a esta doble populismo (el fiscal y monetaria) que fueron la base, tanto del fracaso de la ortodoxia liberal, como del desarrollismo populista, para promover el crecimiento con estabilidad. Poco a poco, como la nueva elaboración teórica desarrollista fue ganando cuerpo, y se centró en el análisis de la tasa de cambio y el déficit en la cuenta corriente, se hizo evidente que nos enfrentamos a una nueva escuela de pensamiento, un paso hacia adelante desde el desarrollismo clásico, que se había equivocado en defender el crecimiento de la 
deuda externa, y la macroeconomía postkeynesianas que comete el mismo error de no tener una contribución satisfactoria en términos de macroeconomía abierta.

Podemos distinguir en las nuevas teorías desarrollistas tres sub-disciplinas: economía política, que ya dedica una sección en este documento; una microeconomía, todavía poco desarrollada; y la macroeconomía que han alcanzado un grado razonable de sofisticación. ${ }^{8}$ La economía política del nuevo desarrollismo se centra en cuestiones tales como la formación del Estado-nación, el papel de las coaliciones de clase para el nuevo desarrollo en el proceso de la revolución industrial y capitalista, y la crítica del imperialismo moderno, que busca convencer a los países en desarrollo a incurrir en déficit en cuenta corriente para tratar de crecer. Ella explica la resistencia de los políticos y los economistas del desarrollo para contrarrestar la tendencia a la sobrevaloración cíclica y del tipo de cambio crónica con el concepto de populismo fiscal, generalmente asociado a un keynesianismo común, que hace caso omiso de la importancia de las finanzas públicas equilibradas en el largo plazo y la búsqueda del consumo inmediato. La economía política desarrollista también explica la resistencia de la teoría económica ortodoxa para defender un tipo de cambio competitivo con el interés de los países ricos en un tipo de cambio apreciado en los países en desarrollo, lo cual genera déficit en la cuenta corriente, que a su vez, legitima o hace "necesaria" la inversión extranjera directa y el financiamiento en moneda extranjera. Por último, explica la incapacidad de los países en desarrollo para salir de esta trampa debido a la alta preferencia por el consumo inmediato de las personas, y la pérdida de la idea de nación por las élites locales. Por lo tanto, bajo el paradigma de tipo de cambio populista, los trabajadores tienen en el corto plazo, mayores salarios reales, rentistas locales, intereses, dividendos y rentas también con mayor poder adquisitivo; y los países ricos siguen ocupando el mercado doméstico en los países en desarrollo con sus préstamos y sus multinacionales, a cambio de un mayor consumo en el corto plazo.

Las altas tasas de interés y su acompañante, el intercambio sobreapreciado, interesan directamente a los rentistas y los capitalistas financieros que manejan la riqueza. En Brasil, además de estas preocupaciones, hay una explicación "técnica" para conseguir altas tasas de interés. Desde 1996, la tasa básica de interés -la tasa Selic-, debe regular las operaciones de mercado abierto y la cantidad de moneda en circulación, es la misma para remunerar la participación de los títulos públicos en el mercado. Por lo tanto, cuando hay un exceso de liquidez en el mercado y la tasa de interés tiende a caer, las pérdidas bancarias no suceden porque los rentistas y sus intermediarios, los bancos, no están obligados a utilizar sus reservas para comprar bonos del tesoro a una tasa menor de lo que se desea, al igual que en otros países. En lugar de ello, pueden recurrir a "acuerdos de recompra", que son a corto plazo y

8 Sólo en cuanto a libros ya publicados, tenemos Macroeconomía de estancamiento (2007) La globalización y la competencia (2009), Bresser-Pereira, Macroeconomía del Desarrollo (2016), Bresser-Pereira, Marconi y Oreiro, y Macroeconomía del Desarrollo: Una perspectiva Keynesiana (2016) de Oreiro. Los tres primeros libros tienen versión en Inglés; En el último José Luis Oreiro hace una gran revisión de los modelos keynesianos y kaleckisianos de desarrollo y los compara con los modelos del nuevo desarrollismo. 
que también se pagan con la tasa Selic. En consecuencia, el Banco Central está obligado a retirarse, porque no están encontrando compradores para la deuda pública, y la tasa de interés no baja cómo se espera.

\section{Teoría económica}

La nueva microeconomía desarrollista recupera las contribuciones de la microeconomía clásica, que se fundamenta en la teoría del valor del trabajo y la tendencia a la igualación de las tasas de ganancia. Ella trabaja con los conceptos de cambio estructural, la transferencia de mano de obra para las industrias más desarrolladas productivamente, que pagan mejores salarios y que implican un mayor valor agregado per cápita, los rendimientos crecientes a escala, y propuestas para la política industrial estratégica que complementan el equilibrio de los precios macroeconómicos, no para compensar su desequilibrio.

La política industrial tiene, por supuesto, un espacio dentro del nuevo desarrollismo, pero esto significa que el potencial de esta política fue sobrestimado. Sin duda fue importante para los países de Asia oriental, como lo demuestran los notables libros de Chalmers Johnson (1982), Alice Amsden (1989) y Robert Wade (1990), de Japón, Corea del Sur y Taiwán. Pero los lectores no prestaron la debida atención al hecho de que en estos países, una política macroeconómica activa, sobre todo una política de tipo de cambio, mantuvo a los cinco precios macroeconómicos adecuada, muy cerca de ser correcta. Política industrial y, dentro de ella, la política de apoyo a las tecnologías, es especialmente importante para la producción competitiva de bienes con un alto valor agregado. Como se ha señalado en el trabajo con Carmen Feijó y André Nassif "No hay una política industrial capaz de tener éxito con el fin de promover el cambio estructural y el proceso de convergencia, si los precios macroeconómicos (inflación, tasas de interés real, la tasa de cambio real y la tasa los salarios reales) no están en niveles adecuados."

La nueva macroeconomía desarrollista es la parte más compleja del nuevo desarrollismo. A diferencia de la macroeconomía convencional, que está muy interesada en los cinco precios macroeconómicos: la tasa de ganancia, lo que debería ser favorable a las empresas para invertir, la tasa de interés, cuyo nivel alrededor del cual el banco central lleva a cabo la política monetaria debe bajar, el tipo de cambio debería convertir a las empresas en competitivas, utilizando la tecnología en el estado del arte en el mundo, la tasa de los salarios que debe ser compatible con el aumento de la tasa de beneficio, y con el aumento de la productividad, finalmente, la tasa de inflación debe ser muy baja. Sin embargo, el mercado definitivamente no garantiza que estos precios macroeconómicos siguen siendo viables. El aporte teórico de la macroeconomía desarrollista es sólido, principalmente del tipo de cambio y el saldo de la cuenta corriente. Para otros precios macroeconómicos y las facturas de impuestos no hay nada realmente nuevo que añadir a la macroeconomía postkeynesianas.

La macroeconomía del desarrollo contiene una nueva teoría de la determinación de la tasa de cambio, la teoría del valor de la moneda extranjera, que establece el nivel de la tasa de cambio, la oferta y demanda de esa moneda, haciendo flotar el tipo de cambio en torno de su valor. Afirma la existencia, en los países en desarrollo, la 
tendencia a la sobrevaluación cíclica y crónica (a largo plazo) del tipo de cambio de la tasa objetivo. Esto no es sólo volátil, como se ha dicho en otras teorías económicas, su volatilidad tiene un sentido o lógica -la tendencia cíclica y crónica- que tiene dos consecuencias principales: en primer lugar, hace que el desarrollo del tipo de cambio sea más predecible; en segundo lugar, da cabida a un cambio fundamental en la función de inversión. 9

La macroeconomía keynesiana revolucionó la función de inversión para argumentar que la tasa de ganancia esperada depende de la demanda y que esto no estaba asegurada debido a la tendencia a la insuficiencia de la demanda; el nuevo desarrollismo ofrece su contribución a la función de inversión que incluye el tipo de cambio. La razón de esto es muy simple: es el tipo de cambio que da o restringe el acceso a la demanda existente, tanto en el país como en el extranjero.

Cuando es apreciado el tipo de cambio entre dos crisis financieras, conforme a lo previsto por el modelo, la tendencia a la sobrevaluación es cíclica y crónica, y las empresas hacen sus cálculos en el largo plazo y si la moneda nacional sigue apreciada, no invierten.

El primer modelo de la nueva teoría desarrollista (....) fue fundamental para el crecimiento de la deuda externa, es decir, con déficit en cuenta corriente financiado por ahorro externo. Aunque parece lógico que los países ricos transfieran su capital a los países pobres en la capital, esta tesis es generalmente falsa.

El déficit de la cuenta corriente corresponde a un tipo de cambio sobrevaluado que resta competitividad a las industrias en el país, y desalienta la inversión, por lo que, después de todo, el consumo es una mejor palanca para las inversiones como consecuencia del "ahorro externo". Sólo en tiempos muy especiales, cuando la economía ya está creciendo a un ritmo acelerado y la propensión marginal al consumo cae, las altas tasas de sustitución de ahorro interno son bajos, y entonces vale la pena recurrir al ahorro externo.

El modelo de alta tasa de sustitución de ahorro interno por ahorro de ahorro externo recomienda que los países no incurren en un déficit en la cuenta corriente; un segundo modelo nuevo-desarrollista, o modelo de enfermedad holandesa nos lleva a concluir: un país que neutraliza la enfermedad holandesa necesariamente debe tener un superávit en la cuenta corriente.

9 La tendencia a la sobrevaloración del tipo de cambio cíclico y crónica fue formulado originalmente en la edición francesa de Mondialisation et competencia (Bresser-Pereira 2009); en ese momento la economía brasileña se encontraba en medio de uno de esos ciclos que comenzaron con la crisis financiera de 1998-1999 y 2002, en el que el verdadero depreció fuertemente y el país comenzó a mostrar superávit en la cuenta corriente. A partir de 2007, sin embargo, el país entra en déficit en cuenta corriente y durante ocho años la tasa de cambio de Brasil en términos reales girará en torno a $\mathrm{R} \$ 2.50$ por dólar, mientras que la balanza industrial fue de $\mathrm{R} \$ 3.50$; debido al aumento del índice comparativo de los costes laborales unitarios en Brasil este equilibrio sube al llegar a R \$ 3.80 por dólar en 2014, cuando una crisis financiera (empresas industriales) causada por las tasas de ganancia muy bajos y la fuerte caída los precios de las materias primas en la segunda mitad del año, conducen a nuevo y fuerte depreciación del real, mientras que la economía brasileña entró en una profunda recesión. 
La tasa de cambio de equilibrio -que equilibra intertemporalmente la cuenta corriente del país- es la tasa de cambio de equilibrio corriente. Cuando no hay enfermedad holandesa, hay una segunda tasa de cambio de equilibrio -el tipo de cambio de equilibrio industrial- lo que hace que las exportaciones competitivas de los bienes comerciables no relacionadas con productos que utilizan las nuevas tecnologías. $Y$ en este caso, como ha señalado Ricardo Bielschowsky el equilibrio actual deja de ser un verdadero equilibrio: se trata de un "equilibrio de bajo crecimiento". Podemos definir la enfermedad holandesa como una elevación del tipo de cambio de un país a largo plazo, porque éste es capaz de exportar materias primas y obtener beneficios a un tipo de cambio sustancialmente más apreciado que el tipo de cambio que hace competitivas a las otras empresas industriales: el equilibrio industrial.

Al contrario de lo que ocurre en el modelo teórico neoclásico de la enfermedad holandesa (Corden y Neary, 1982; 1984), el modelo de Bresser-Pereira (2008) este desequilibrio o puede ocurrir independientemente de la existencia de un auge de los commodities o una desventaja competitiva, simplemente debido al hecho de que el beneficio de los commodities de rentas ricardianas. También a diferencia del modelo Corden y Neary, el nuevo modelo desarrollista muestra que la neutralización de la enfermedad holandesa provoca el desplazamiento del saldo actual de la industria, y por lo tanto, implica un superávit en la cuenta corriente. Para lograr esta neutralización, aboga por una política simple y clara. A medida que la enfermedad holandesa es la diferencia entre el saldo industrial y el corriente, un impuesto o retención de divisas es igual a la diferencia entre el saldo actual e industrial, neutraliza la enfermedad holandesa al hacer iguales a los dos equilibrios. La tasa de cambio de los países exportadores de materias primas varía principalmente con un cambio en sus precios, ya que determinan el equilibrio corriente. ${ }^{10}$ Con la retención cambian las variables de acuerdo con los precios internacionales de las materias primas, los exportadores de productos ahora tienen un ingreso estable, independientemente de la variación del precio internacional de cada producto; lo que pagan en retenciones, se devuelve en forma de apreciación de la moneda.

El nuevo desarrollismo es crítico de la balanza de modelos de crisis de pagos con base en la irresponsabilidad fiscal (Krugman: 1979 1999).

A pesar de la expansión fiscal puede explicar la crisis de balanza de pagos, su opinión es que se origina principalmente por déficit en cuenta corriente crónica, causada por tres "políticas habituales" en los países en desarrollo: crecimiento con ahorro o endeudamiento externo, política de tipo de cambio fijo frente a la inflación y las alzas de tasas de interés para atraer capital, combatir la inflación y lograr la "profundización financiera" de hablar con la teoría económica ortodoxa desde la década de 1970 para convencer a los países en desarrollo para elevar las tasas de interés.

En resumen, al comparar el nuevo desarrollismo con el desarrollismo clásico, me gustaría señalar algunas diferencias básicas:

10 Diez tesis neo-desarrollismo fueron discutidas y aprobadas por un grupo de macroeconomistas y los economistas del desarrollo en Sao Paulo en mayo de 2010, y luego fueron firmados por un total de 87 economistas y politólogos. Ver http://bit.ly/2ea3Lzw. 
1. El desarrollismo clásico tenía como objeto principal los países preindustriales; el nuevo desarrollismo, los países de ingresos medios, que han llevado a cabo su revolución industrial capitalista

2. El desarrollismo clásico se basa en la tesis de la protección de la industria naciente y la industria nacional; el nuevo desarrollismo demanda condiciones equitativas de competencia para las empresas industriales, que no cuentan con esta igualdad, principalmente por que su tipo de cambio tiende a ser sobrevalorados en el largo plazo

3. El desarrollismo clásico defendia la política de crecimiento con endeudamiento externo; el nuevo desarrollismo la rechaza

4. El desarrollismo clásico defendió el modelo de sustitución de importaciones; el nuevo desarrollismo, un modelo basado en la exportación de productos manufacturados soportados sobre un tipo de cambio de equilibrio industrial o competitiva; en otras palabras, el nuevo desarrollismo defiende una integración internacional competitiva de los países en vías de desarrollo, en lugar de una integración subordinada

\section{Determinación del tipo de cambio}

El nuevo desarrollismo tiene una nueva teoría sobre la determinación

de la tasa de cambio. Al igual que cualquier producto, su precio -el precio de la moneda extranjera- depende del valor de la mercancía, y en este caso, que depende del valor de la moneda extranjera. El precio de mercado y los tipo de cambio nominal y real varía en torno a este valor en función de la oferta y la demanda de divisas, pero esto tiene un valor que puede ser definido simplemente. La cantidad de moneda extranjera y la cantidad que cubren satisfactoriamente las sociedades con el lucro de las empresas que participan en el comercio exterior del país, garantizan el equilibrio intertemporal de la cuenta corriente. Yo llamo a este valor "saldo actual", el valor de la tasa de cambio que asegura el equilibrio intertemporal de la cuenta corriente del país.

El tipo de cambio del precio fluctúa en torno a este valor debido a las tres políticas habituales mencionados anteriormente, que atraen capitales del exterior: la política de crecimiento con un déficit en la cuenta corriente o de ahorros "extranjeras", la política de tipo de cambio fijo frente a la inflación y el alto nivel de la tasa de interés. Otros factores que pueden afectar la oferta y la demanda de divisas; especialmente el cambio en la relación de intercambio. La tasa de cambio de equilibrio en cualquier economía nacional es la tasa de equilibrio. Pero cuando existe la enfermedad holandesa durante dos equilibrios: la corriente, en relación con las commodities, e industrial, con relación a los bienes comercializables y no mercancías.

La balanza industrial es el verdadero equilibrio competitivo, que hace que las empresas competitivas que utilizan la mejor tecnología disponible en su sector. ¿Como se comporta el tipo de cambio de mercado? ¿De qué depende? Para las teorías convencionales, el tipo de cambio fluctúa volatilmente todo el saldo actual; para la macroeconomía del desarrollo también fluctúa en torno al equilibrio de manera volatil, pero la volatilidad es demasiado vaga para calificar el tipo de cambio. Es volátil, pero su fluctuación no se produce al azar, sigue un patrón: la tendencia a la sobrevaloración del tipo de cambio cíclico y crónica. Esta tendencia es, por tanto, crítica para determinar el tipo de cambio, y nos permite tener algunas predicciones sobre lo que 
sucederá. También creemos que el tipo de cambio en términos de acciones en lugar de en términos de flujo. Para cada saldo de la cuenta corriente (una acción) hay un tipo de cambio correspondiente. El tipo de cambio que equilibra la cuenta corriente de un país se deprecia más que el tipo de cambio de "equilibrar" un déficit en la cuenta corriente de $3 \%$ del PIB. Dos Figuras nos ayudan a comprender la determinación de la tasa de cambio. Podemos ver en la 1 que el equilibrio entre la cuenta corriente y el tipo de cambio existe una relación lineal directa. Cuanto más negativo sea el equilibrio, la tasa de cambio más apreciado es, y viceversa. Así que cuando un país decide tratar de crecer con ahorro externo, es decir, el déficit en la cuenta corriente financiado ya sea mediante inversión directa o préstamos, debe decidir apreciar su tipo de cambio, que para cada saldo de la cuenta corriente no sea un tipo de cambio diferente, y el equilibrio es un solo punto -es el punto de la curva de la cuenta corriente con respecto al equilibrio- el tipo de cambio cruza la línea vertical y marca el saldo actual, es decir, el tipo de cambio en que el cuenta corriente es equilibrada o igual a cero.

Esta línea recta está inclinada, hacia arriba y hacia la derecha, lo que significa que cuanto más infravalorado el tipo de cambio, mayor es el superávit en la cuenta corriente, y viceversa. $Y$ una relación lineal inclinada. Pero hay factores que hacen que se mueva hacia arriba o hacia abajo. Los dos principales son las relaciones de cambio, o, más simplemente, la variación de los precios internacionales de las commodities, y las variaciones en el índice comparativo de los costes laborales unitarios. Teniendo en cuenta sólo los factores que influyen más, respectivamente, el saldo actual y el equilibrio industrial, cuando los precios caen, el saldo actual sube y viceversa; Por otra parte, cuando el índice comparativo eleva los costes laborales unitarios en relación al bien no comercializable, de equilibrio industrial aumenta, y viceversa.

Figura 1

Déficit en cuenta corriente y tasa de cambio

Figura 2 Dos equilibrios y una tasa de cambio
Déficit encuenta corriente y tasa de cambio

Dos equilibrios y una tasa de cambio
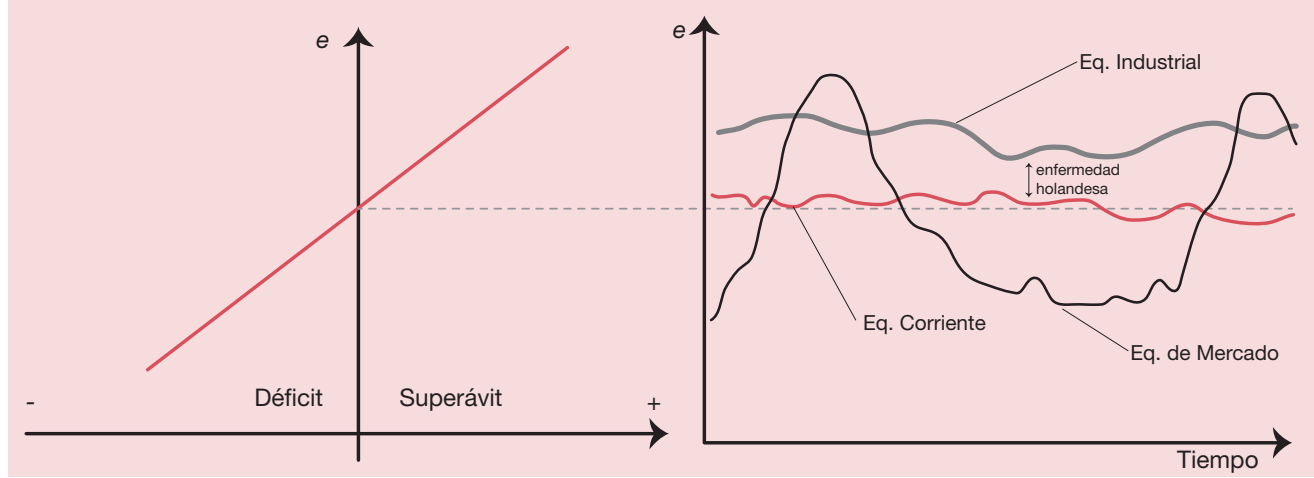

En la Figura 2 tenemos el saldo actual, el industrial y el precio de mercado del tipo de cambio. Esto sigue la tendencia cíclica: se deprecia con violencia en tiempos de crisis financiera, a continuación, se aprecia, cruza las líneas de la balanza industrial y el saldo actual y se mantiene durante unos años en la cuenta corriente de la zona del déficit hasta que el aumento de la deuda (deuda corporativa o interna) externa causa nueva crisis financiera y el tipo de cambio se vuelve a depreciar. Cuando no 
hay enfermedad holandesa, el equilibrio industrial es igual al corriente; cuando existe, el equilibrio corriente será más distante de la balanza industrial cuanto más «grave» es la enfermedad holandesa, es decir, las rentas más ricardianas en un lado y el auge de los commodities en el otro, se convierten en los dos valores más distantes uno del otro. La distancia entre los dos balances o valores es la enfermedad holandesa

Cuando, después de una crisis financiera en la que el tipo de cambio se depreció fuertemente, el tipo de cambio hacia atrás para disfrutar de primera enfermedad holandesa "tira" al saldo actual (que está determinada por la rentabilidad de los commodities; a continuación, hasta por debajo de la balanza por cuenta corriente, impulsada por las tres políticas habituales, y el déficit en la cuenta corriente que se acumulan y el aumento de la deuda externa hasta que los prestamistas externos pierden la confianza, desatan una nueva crisis de la moneda, y la moneda nacional de nuevo se vuelve a depreciar bruscamente, completando el ciclo.

La Figura 2 muestra la tasa de cambio real siguiendo el patrón cíclico que acabo de describir

Las dos Figuras están acopladas, al saldo actual, en la que no hay tiempo sino que equivale, que corresponde aproximadamente al saldo actual en cada momento de tiempo medido en abscisas en la Figura 2, digo aproximadamente porque la línea del saldo actual en el tiempo varía de acuerdo a los términos del país del comercio y los cambios en el índice comparativo de los costes laborales unitários. Por lo tanto, para cada uno de estos puntos en la Figura 2 no es teóricamente una cuenta corriente de la balanza de línea-tipo de cambio.

El nuevo desarrollismo y distribución En la teoría económica existe un falso debate que se opone al modelo de crecimiento basado en las exportaciones y a los incrementos salariales para centrarse en el mercado interno. De hecho, se puede tener una economía para el mercado interno, y por lo tanto, contar con el aumento de salarios para garantizar la demanda de las empresas. Sin embargo, esta estrategia sólo será posible si vamos a volver al modelo de sustitución de importaciones. Es decir, si tenemos que volver a tener altas tarifas de importación y reducir la apertura. El nuevo desarrollismo rechaza el liberalismo económico, en este sentido, no porque quieran cerrar las economías nacionales, sino porque quiere integrarse de manera competitiva y no subordinados al sistema internacional. El país se integra de manera subordinada cuando acepta déficit en la cuenta corriente y la consiguiente ocupación del mercado interno por los grandes países; se integra de forma competitiva cuando tiene un tipo de cambio competitivo y asegura la igualdad en las condiciones de competencia. La integración en cadenas de valor solo vale la pena si los países en desarrollo no se limitarán a la fase de producción intensiva en trabajo poco cualificado, y sólo se puede superar este límite si sus empresas cuentan con un tipo de cambio competitivo. El modelo de sustitución de importaciones sólo es eficaz en el inicio de la industrialización, y por un breve periodo de tiempo. Luego hay que abrir la economía y competir. Por último, hay que recordar que históricamente la estrategia impulsada por los salarios no ha cumplido con la reducción, sino, más bien, con el aumento de las desigualdades. La 
única ventaja clara par los países en desarrollo en relación con los países ricos son sus bajos salarios.

Es absurdo no aprovechar esta ventaja, especialmente porque, como hemos visto drásticamente en China, es a través de esta estrategia que los salarios comienzan a aumentar. En términos más generales, hay un gran error en relación con la distribución del ingreso entre los economistas del desarrollo y keynesianos. Se refiere a la reducción de las desigualdades, y esto es esencial. En la democracia, el desarrollismo debe ser de tipo social y ambiental. Debe ser social, no sólo por el bien de la justicia, sino también porque en una democracia los electores reclaman que no hay distribución. El problema es cómo hacerlo. No se debe hacer a través de un modelo dedicado a la creciente demanda por el aumento de los salarios, por encima de la productividad, debido a esto reduce la tasa de ganancia, las inversiones y el empleo, sino los resultados serán inflacionarios.

A nivel macroeconómico, la única política incuestionable es un intento de rebajar el nivel de las tasas de interés, porque mientras una tasa de ganancia satisfactoria es necesario para que las empresas inviertan, las alta tasa de interés en torno al cual el banco central aplica su política monetaria sólo es perjudicial para la inversión y el crecimiento. Entonces, ¿cuál debe ser la política distributiva del gobierno? Además de conseguir un salario mínimo decente, se debe considerar un amplio sistema de bienestar basado en garantizar derechos universales a la educación básica, la salud y una vejez digna, financiado por un sistema fiscal progresivo. La gran diferencia entre la distribución en los países escandinavos y Estados Unidos, entre los países más igualitarios y la más desigual entre los países ricos, no sucede antes de impuestos, pero sí después de ellos. En Estados Unidos el sistema fiscal progresivo creado por la administración democrática y de desarrollo del presidente Franklin Delano Roosevelt fue desmantelada por el gobierno neoliberal del presidente Ronald Reagan, lo que hizo de Estados Unidos un país profundamente desigual y con una sociedad dividida.

\section{Política macroeconómica} los cinco precios macroeconómicos, por qué el mercado no lo hace ni los garantiza, como lo podemos ver en las crisis económicas y financieras, de acuerdo con las definiciones dadas anteriormente. Los objetivos de la política macroeconómica son el pleno empleo y la estabilidad financiera y de precios. Para lograrlos, el nuevo desarrollismo no hace mas que acrecentar la política monetaria y la política fiscal postkeynesianos. Sólo es importante señalar que la macroeconomía desarrollistas hace hincapié en la responsabilidad fiscal, es decir, el equilibrio en el gasto público a largo plazo, que debe observar un comportamiento contracíclico, y en el mantenimiento de la deuda pública a un nivel razonable. Para el nuevo desarrollismo los déficit fiscales crónicos son el populismo fiscal.

La política de tipo de cambio que la ortodoxia liberal rechaza, es fundamental para el nuevo desarrollismo. No defiende la guerra de divisas, pero sostiene que el tipo de cambio fluctúe alrededor de la balanza industrial. Para ello -para que las empresas productivas sean competentes- la política de tipo de cambio debería neu- 
tralizar la enfermedad holandesa y, en términos más generales, la tendencia a la sobrevaloración del tipo de cambio cíclico y crónica, que también se debe a las tres políticas habituales. Para neutralizar la enfermedad holandesa, de manera completa es esencial para establecer un impuesto o retención de divisas para cambar esa desventaja competitiva. Ese impuesto aumenta el valor del equilibrio corriente, es decir, las empresas con fines de costes más satisfactorios que participan en el comercio exterior, por lo que, es igual a la de equilibrio industrial. Para evitar que el país incurra en un déficit en la cuenta corriente, el rechazo de las tres políticas habituales, en general, con el apoyo de la ortodoxia liberal, debe ser clara y decisiva.

Hay muchos objetivos de la política macroeconómica, pero se requiere que el operador de ellas defina un único objetivo, y no serían metas de inflación, o de crecimiento; pero los saldos de la cuenta corriente y la meta de equilibrio deberá ser cero, sino, el país sufrirá de la enfermedad holandesa, y tendía que ser superavitario si la severidad de la enfermedad holandesa aparece, es decir, con mayor diferencia entre el saldo actual y industrial.

El nuevo desarrollismo no es una política fiscal original. Rechaza los déficit crónicos, y adopta la teoría post-keynesiano. A corto plazo, la política fiscal debe ser estrictamente anticíclica; en el largo plazo, tiene que fomentar el ahorro público, además de un déficit primario y no aumentar la relación de deuda pública/PIB, para financiar de manera satisfactoria las inversiones públicas, lo que debería ser, en principio, entre 20 y $25 \%$ de la inversión total. Para argumentar que no hay déficit y luego equilibrio o superávit en la cuenta corriente, la responsabilidad fiscal y la rendición de cuentas de auto-refuerzo es importante. Cuando el tipo de cambio es equilibrado y el país está llevando a cabo un superávit de cuenta corriente tiende a ocurrir el fenómeno del doble déficit. Dado que el objetivo es un superávit en la cuenta corriente, también podría ser un superávit fiscal, pero en realidad un pequeño déficit público no aumenta la deuda pública/PIB pues será aceptable.

El nuevo desarrollismo defiende una carga tributaria relativamente alta para financiar los grandes servicios sociales universales. No sólo porque estos grandes servicios son más justos, sino también porque son más económicos que aumentar los salarios. Se cree, sin embargo, que el aumento de la presión fiscal no debe ser el resultado del hecho consumado, pero la discusión será fruto de la negociación política. En las sociedades que asumen que son democráticas, el capitalismo no puede ser sólo del desarrollo; debe ser también social. Y hay un problema en el corto plazo: existe una relación inversa entre la tasa de cambio y los salarios reales. Debemos tener en cuenta que existe la misma relación de los ingresos de los rentistas: intereses, dividendos, rentas

Cuando la tendencia a la sobrevaloración del tipo de cambio es cíclico y crónico se neutraliza y los cinco precios macroeconómicos, cuentan con certidumbre, la tasa de ganancia de las empresas no relacionadas con productos comercializables aumenta, y caen los rendimientos en el corto plazo. Pero debemos aceptar este sacrificio en el corto plazo. Sin embargo, el nuevo desarrollismo es necesariamente social y, por tanto, aboga por la política activa de reducción de las desigualdades, las cuales, si se deja al mercado tendran costos sociales muy altos. ¿Qué políticas 
son esas? La expansión fiscal es una solución mágica a todos los problemas, pues hay mucho menos austeridad en todas las circunstancias, pero el aumento del gasto social del Estado y su financiación deben ser a través de un sistema fiscal progresivo. Lo que hace a las sociedades escandinavas más iguales que a Estados Unidos no son políticas fiscales expansivas, con una elevada carga tributaria, sino con impuestos progresivos.

\section{Conclusión}

El primer desarrollismo históricamente existentes, tanto mercantilista como bismarquiano, eran autoritarios. Lo mismo debe decirse del desarrollismo nacional y desarrollismo de Asia Oriental. El segundo desarrollismo, después de la Segunda Guerra Mundial, era democrático y social. Un tercer desarrollismo nace del gran fracaso económico y político de la globalización (dominio de las empresas multinacionales), la financiarización (dominancia adicional del sector financiero) y el neoliberalismo (liberalismo económico radical que interesa a los rentistas capitalistas). Que además de garantizar en los países en desarrollo, la democracia y la reducción de las desigualdades, es preciso proteger el medio ambiente. ¿Este tercer desarrollismo es posible? No puedo garantizarlo, pero no estoy dispuesto a aceptar la tesis pesimista de que el progreso o el desarrollo humano son meras ilusiones; no estaban aquí; no tienen ninguna razón de ser. Hay un gran pesimismo en los países ricos porque los países en desarrollo compiten con ellos en la exportación de productos manufacturados desde 1970 y es cada vez más intensa. Para hacerles frente necesitan reducir los salarios en los países ricos y sus elites económicas adoptan el neoliberalismo y proponen que la situación sea aún más precaria. Así vemos una verdadera lucha de clases desde la alta hacia la baja, en que las élites neoliberales ejercen su poder económico y hegemonía ideológica agresiva. No se dan cuenta de que al hacerlo, añaden a la crisis económica una crisis política.

En cuanto a las élites económicas en los países en desarrollo, o que son nacionales y desarrollista, y están asociados con su pueblo, o son dependientes y liberales, o se asocian con las élites de los países ricos. Las élites de los países de Asia oriental han adoptado la primera alternativa y se realizó el acercamiento, pues las élites latinoamericanas se quedaron con la segunda alternativa, y sus países permanecen casi estancada ya que los países ricos están casi estancadas.

El nuevo desarrollismo no es una nueva ortodoxia; se trata de un sistema teórico abierto en el que encaja muchas versiones. Tal vez sólo tres cosas son esenciales para que alguien se sienta parte de ella: la idea del desarrollo como un cambio estructural, heredado del desarrollismo clásico; la tesis del crecimiento impulsado por la demanda, heredado de Keynes y Kalecki; y la tendencia a la sobrevaloración del tipo de cambio cíclico y crónico. El nuevo desarrollismo es o pretende ser una renovación del desarrollismo clásico de nuestros maestros comunes, Raul Prebisch y Celso Furtado. Diverge en un punto: el crecimiento con ahorro externo; y una macroeconomía del desarrollo que explica lo que los economistas del desarrollo del pasado para neutralizar la enfermedad holandesa y así neutralizar la grave desventaja competitiva que un tipo de cambio apreciado propicia en el largo plazo. 


\section{Referencias}

Amsden, Alice H. (1989) Asia’s Next Giant. New York: Oxford University Press.

Bresser-Pereira, Luiz Carlos (2008) “The Dutch disease and its neutralization: a Ricardian approach" (2008) Brazilian Journal of Political Economy 28 (1): 47-71. (445)

Bresser-Pereira, Luiz Carlos (2009) Globalização e Competição. Rio de Janeiro: Elsevier-Campus.

Bresser-Pereira, Luiz Carlos (2016a) "Models of developmental state", Texto para Discussão EESP/FGV n. 426, setembro 2016. Disponível no website do autor: www.bresserpereira.org.br.

Bresser-Pereira, Luiz Carlos (2016b) "Democracy and development in pre-industrial countries". Texto para Discussão EESP/FGV 410, janeiro 2016.

Bresser-Pereira, Luiz Carlos e Fernando Rugitsky (2015) "Industrial policy and exchange rate skepticism". Department of Economics FEA/USP, Working Paper Series 2016-08.

Bresser-Pereira, Luiz Carlos, André Nassif e Carmem Feijó (2016) "A reconstrução da indústria brasileira: a conexão entre o regime macroeconômico e a política industrial". Revista de Economia Política 36 (3): 493-513.

Corden, W. M. and J. P. Neary (1982) "Booming sector and de-industrialization in a small open economy", Economic Journal 92 (368): 825-848.

Corden, W. M. and J. P. Neary (1984) "Booming sector and Dutch disease economics: survey and consolidation". Oxford Economic Papers, 36 (3): 359-380.

Furtado, Celso (1961) Desenvolvimento e Subdesenvolvimento, Rio de Janeiro: Editora Fundo de Cultura. Nova edição: Centro Internacional Celso Furtado/Contraponto, 2009.

Hamilton, Alexander (1791 [2001]) Report on Manufactures, relatório ao Congresso dos Estados Unidos em sua qualidade de Secretário do Tesouro. Escaneado em janeiro de 2001 a partir de fontes primárias. http://bit.ly/1FaVTTg

Hirschman, Albert O. (1981) "The rise and decline of development economics", in Essays in Trespassing. Nova York: Cambridge University Press: 1-24.

Johnson, Chalmers (1982) MITI and the Japanese Miracle, Stanford: Stanford University Press.

Kohlscheen, Emanuel (2014) “Long-Run Determinants of the Brazilian Real: a Closer Look at Commodities", International Journal of Finance \& Economics 9 (4) outubro: 239-250.

Krugman, Paul (1979) "A model of balance of payments crises", Journal of Money Credit and Banking, 11, (3): 311-325.

Krugman, Paul (1999), "What happened to Asia?", in Ryuzo Sato, Rama V. Ramachandran, Kazuo Mino (1999) Global Competition and Integration. Norwell, MA: KIwer Academic Press: 315-327.

List, Friedrich (1846 [1986]) O Sistema Nacional de Economia Política. São Paulo: Editora Nova Cultural, Coleção Os Economistas. Publicação original em alemão, 1846.

Oreiro, José Luis (2016) Macroeconomia do Desenvolvimento: Uma Perspectiva Keynesiana, Rio de Janeiro: LTC.

Prebisch, Raúl (1949) "O desenvolvimento da América Latina e seus principais problemas",. Revista Brasileira de Economia 3(3) setembro 1949: 47-111. Publicação original na introdução de Estudio Económico de la América Latina 1948 (Santiago do Chile: CEPAL, 1949).

Rosenstein-Rodan, Paul (1943) "Problems of industrialization in Eastern Europe and South-Eastern Europe”, Economic Journal 53, junho 1943: 202-211.

Wade, Robert (1990) Governing the Market, Princeton: Princeton University Press. 